\title{
Antibiotic Susceptibility Pattern of Methicillin Sensitive and Resistant Staphylococcus aureus from Clinical Isolates in a Tertiary Care Hospital at Mathura, Western Uttar Pradesh
}

\author{
Kandhakumari Gandhi* (D) and Ashok Kumar Dhanvijay (D) \\ Department of Microbiology, Kanti Devi Medical College and Research Centre, Mathura - 281 406, Uttar Pradesh, \\ India.
}

\begin{abstract}
Staphylococcus aureus causes infection ranging from mild skin infection to fatal life threatening infections. Nowadays, Methicillin resistant Staphylococcus aureus (MRSA) which do not respond to commonly used antibiotics has emerged posing serious threat in health care settings which aimed to study the susceptibility pattern of MSSA and MRSA among inpatients and outpatients in our hospital. This study included 159 strains of $S$. aureus isolated from various clinical specimens collected from April 2018 - March 2019. Standard isolation techniques and identification protocols were followed. Among the total 159 Staphylococcal isolates, 134 isolates and 25 isolates were isolated from inpatients and outpatients respectively. Methicillin resistance was seen in $67.3 \%(107 / 159)$ of the total isolates, among which $69.4 \%(93 / 134)$ were from inpatients and $56 \%(14 / 25)$ were from outpatients. Among these total MRSA, 38\% were reported from urine followed by pus and blood samples. Antibiotic susceptibility pattern revealed that $75 \%$ of MSSA strains were sensitive to doxycycline and Clindamycin. Among the MRSA isolates 95.3\% were resistant to Ampicillin and 86.9\%, 73.8\%, 60.7\%, 52.3\% and 50.4\% isolates were resistant to erythromycin, Co-trimoxazole, Ciprofloxacin, Moxifloxacin and Clindamycin respectively. All MRSA isolates were sensitive to vancomycin while $97.2 \%$ were sensitive to Linzolide. S. aureus isolated from urine showed high resistance of $89 \%$ and sensitivity of $\mathbf{9 2 . 7 \%}$ to norfloxacin and nitrofurantoin respectively. This study reports high prevalence of MRSA. This study helps to select the appropriate antibiotic for proper patient care in this area and insist upon to follow strict hospital Infection control practices in this hospital.
\end{abstract}

Keywords: Staphylococcus aureus, MRSA, Cefoxitin, MSSA, Antimicrobial resistance

*Correspondence: gkandha_micro@yahoo.com; +91-7667680216

(Received: January 16, 2020; accepted: February 08, 2020)

Citation: Kandhakumari Gandhi and Ashok Kumar Dhanvijay, Antibiotic Susceptibility Pattern of Methicillin Sensitive and Resistant Staphylococcus aureus from Clinical Isolates in a Tertiary Care Hospital at Mathura, Western Uttar Pradesh, J. Pure Appl. Microbiol., 2020; 14(1):455-460. https://doi.org/10.22207/JPAM.14.1.47

(C) The Author(s) 2020. Open Access. This article is distributed under the terms of the Creative Commons Attribution 4.0 International License which permits unrestricted use, sharing, distribution, and reproduction in any medium, provided you give appropriate credit to the original author(s) and the source, provide a link to the Creative Commons license, and indicate if changes were made. 


\section{INTRODUCTION}

Staphylococcus aureus is a leading cause of pyogenic bacterial infection in humans worldwide and is well known for its ability to develop drug resistance. S.aureus has traditionally been the leading cause of skin and soft tissue infections and the severity may vary from benign impetigo to life threatening infections. It is commonly isolated from cutaneous abscesses, purulent cellulitis and surgical site infections. In the early 1960s, Methicillin Resistant S.aureus (MRSA) emerged as a potential pathogen causing nosocomial colonization, several outbreaks and difficult-to-treat infections like bacteremia, infective endocarditis, osteoarticular and pleuropulmonary infections. They also causes device related infections like central line associated blood stream infections, ventilator associated pneumonia and catheter associated urinary tract infections ${ }^{1-5}$. It always remains a challenge for physicians to treat and control MRSA infections. While infections by Methicillin Sensitive S.aureus (MSSA) remain stable, infections due to MRSA fluctuated. Patients in intensive care units (ICUs) and with chronic diseases like diabetes, cancer, vascular diseases and eczema are at greater risk of acquisition of MRSA infections due to hospital stay after invasive procedures and weekend immune system ${ }^{5}$. Further, people with open draining wounds and infections spread the MRSA in the community. As reviewed by Gupta et al., ${ }^{6}$ nosocomial infections caused by MRSA increased from $30 \%$ in 1990 's to $80 \%$ in 2010 in many countries. In India, it varies from $29 \%$ in 2009 to $47 \%$ in $2014^{3}$. This increasing rate of infections caused by MRSA pose a serious treat causing extensive difficult to control outbreaks. Moreover the drugs used to treat MRSA infections are highly expensive and potentially toxic. Hence this study aimed for the early detection of MRSA by screening and to determine the invitro susceptibility pattern to various antimicrobial agents which helps to choose the appropriate drug for treatment.

\section{MATERIALS AND METHODS}

This prospective work was carried out in the microbiology laboratory of a tertiary care teaching hospital at western Uttar Pradesh for a period of one year from April 2018 to March 2019 following the ethical guidelines. Various clinical specimens like blood, pus, sputum, pleural fluid, urine, vaginal and ear swabs were included.

\section{Bacterial isolates}

A total of 159 S.aureus strains were isolated from these specimens. Standard techniques ${ }^{7}$ like Gram staining and coagulase test were used for the identification of $S$. aureus.

\section{Antimicrobial susceptibility testing}

Inoculum was prepared from the colonies grown on blood agar plates and antibiotic susceptibility testing was carried out on Mueller Hinton Agar after adjusting the turbidity to $0.5 \mathrm{McFarland}$ standard. Modified Kirby Bauer disc diffusion method was followed for antibiotic susceptibility testing using antibiotic discs like Ampicillin $(10 \mu \mathrm{g})$, Ciprofloxacin $(5 \mu \mathrm{g})$, Clindamycin $(2 \mu \mathrm{g})$ Co-trimoxazole $(1.25 / 23.75 \mu \mathrm{g})$, Doxycycline $(30 \mu \mathrm{g})$ Erythromycin $(15 \mu \mathrm{g})$, Linezolid $(30 \mu \mathrm{g})$ Moxifloxacin $(5 \mu \mathrm{g})$, Nitrofurantoin $(300 \mu \mathrm{g})$ Norfloxacin $(10 \mu \mathrm{g})$, Teicoplanin $(30 \mu \mathrm{g})$ and Vancomycin $(30 \mu \mathrm{g})$ procured from Hi-media. Zone of inhibition was measured and results were interpreted as Susceptible, Intermediate and Resistant following the recommendations of CLSI guidelines ${ }^{8}$. Screening for MRSA was done using

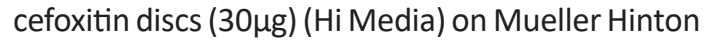
agar and zone of inhibition $\leq 22 \mathrm{~mm}$ indicates methicillin resistance and was reported as MRSA. S. aureus ATCC 25923 was used as standard control strain. Chi-square test was used for the statistical analysis of the data and $p$ values which were $<0.05$ were considered to be statistically significant.

\section{RESULTS}

A total of 159 S. aureus was isolated of which $32.7 \%$ were MSSA and $67.3 \%$ were MRSA. Among the MSSA isolates $38.5 \%$ (20/52) was isolated from pus, $32.7 \%(17 / 52)$ from urine and $21 \%(11 / 52)$ from blood whereas, among the MRSA isolates $35.5 \%(38 / 107)$ was obtained from urine, $29 \%(31 / 107)$ from pus followed by $26.2 \%(28 / 107)$ from blood. Distribution of MRSA and MSSA isolated from different clinical specimen is listed in Table: 1 . Regarding the susceptibility pattern of MSSA, $42.3 \%$ of isolates were sensitive to Ampicillin, 38.5\% were sensitive to Erythromycin, $46.2 \%$ to Ciprofloxacin, $44.2 \%$ to Co-trimoxazole and $48.1 \%$ to Moxifloxacin. Among the MRSA isolates only $4.7 \%$ isolates were sensitive to Ampicillin, $13.1 \%$ to erythromycin, $39.3 \%$ to 
Ciprofloxacin, $26.2 \%$ to Co-trimoxazole, $47.7 \%$ to Moxifloxacin, $86 \%$ to Teicoplanin, and $97.2 \%$ were sensitive to linezolid. Doxycycline and Clindamycin sensitivity was seen in $75 \%$ of the MSSA strains, but among MRSA 64.5\% were sensitive to Doxycyline and $49.6 \%$ were sensitive to Clindamycin. As far as the sensitivity pattern of MRSA is concerned, it showed sensitivity of $100 \%$ and $86 \%$ for Vancomycin and Teicoplanin respectively. Among urinary pathogens $94.1 \%$ of MSSA and $86.8 \%$ of MRSA were resistant to Norfloxacin, while only $11.8 \%$ and $5.2 \%$ were resistant to Nitrofurantoin respectively. The resistance patterns of MSSA and

Table 1. Distribution of MRSA in different clinical samples

\begin{tabular}{lcccc}
\hline No. & $\begin{array}{c}\text { Clinical } \\
\text { samples }\end{array}$ & $\begin{array}{c}\text { S. aureus } \\
(\%)\end{array}$ & $\begin{array}{c}\text { MRSA } \\
(\%)\end{array}$ & $\begin{array}{c}\mathrm{P} \\
\text { value }\end{array}$ \\
\hline 1 & Blood & $39(24.5)$ & $28(26.2 \%)$ & 0.76 \\
2 & Ear Swab & $01(0.6)$ & $1(0.9 \%)$ & 0.7 \\
3 & Pleural fluid & $02(1.3)$ & $1(0.9 \%)$ & 0.80 \\
4 & Pus & $51(32)$ & $31(29 \%)$ & 0.59 \\
5 & Sputum & $8(5)$ & $5(4.7 \%)$ & 0.89 \\
6 & Urine & $55(34.6)$ & $38(35.5 \%)$ & 0.87 \\
7 & Vaginal swab & $3(1.9)$ & $3(2.8 \%)$ & 0.62 \\
8 & Total & $159(100)$ & $107(100)$ & \\
\hline
\end{tabular}

MRSA - Methicillin Resistant Staphylococcus aureus.
MRSA isolated from the outpatient and inpatient samples is presented in Table: 2 and 3.

\section{DISCUSSION}

MRSA poses a serious and constant threat to health care institutions. Data on the prevalence of MRSA is not uniform. Literature has documented a significant variation in the prevalence rate from different parts of India and between countries ${ }^{1-6,9-28}$. Studies from India report MRSA prevalence ranging from $6.9 \%$ to $87 \%{ }^{9}$. A higher percentage have also been reported from other countries like Sudan (45\%), Kenya (53.4\%), Nigeria (73.8\%), Peru (80\%), Rwanda (82\%), and in Colombia $(90 \%)^{4,10-14}$. In the current study we report a prevalence of $67.3 \%$ in this hospital. Other studies have documented $20.3 \%$ of MRSA from Gujarat, 26.14\% from Nepal, 29\% from Mumbai and Mangalore, 53\% from Pune and around $80 \%$ from Bubaneswar showing the varying prevalence of $\mathrm{MRSA}^{15-20}$. This wide variation in prevalence rate might be due to study design, inclusion and exclusion criteria, types of specimen, laboratory protocols, study duration, population included, phenotypic or genotypic characteristics studied etc. All these factors may sometimes overestimate the prevalence of MRSA generated from a single centre study, and this overestimated prevalence rate is generalized throughout the country.

Table 2. Antibiotic susceptibility pattern of MRSA to various antibiotics

\begin{tabular}{|c|c|c|c|c|c|c|c|c|c|c|}
\hline \multirow[t]{2}{*}{ Antibiotics } & \multicolumn{4}{|c|}{$\begin{array}{l}\text { Isolate from in patient } \\
\qquad(93)^{*}\end{array}$} & \multicolumn{4}{|c|}{$\begin{array}{l}\text { Isolate from outpatient } \\
\qquad(14)^{*}\end{array}$} & \multicolumn{2}{|c|}{$\begin{array}{c}\text { Total resistance } \\
\text { (IP + OP cases) } \\
n=107\end{array}$} \\
\hline & $S$ & $\%$ & $\mathrm{R}$ & $\%$ & $\mathrm{~S}$ & $\%$ & $\mathrm{R}$ & $\%$ & $\mathrm{R}$ & $\%$ \\
\hline Ampicillin & 5 & 5.3 & 88 & 94.6 & 0 & 0 & 14 & 100 & 102 & 95.3 \\
\hline Erythromycin & 14 & 15 & 79 & 85 & 0 & 0 & 14 & 100 & 93 & 86.9 \\
\hline Doxycycline & 65 & 69.9 & 28 & 30.1 & 4 & 28.6 & 10 & 71.4 & 38 & 35.5 \\
\hline Clindamycin & 47 & 50.5 & 46 & 49.5 & 6 & 42.8 & 8 & 57.1 & 54 & 50.4 \\
\hline Ciprofloxacin & 38 & 40.9 & 55 & 59.1 & 4 & 28.6 & 10 & 71.4 & 65 & 60.7 \\
\hline Co-trimoxazole & 26 & 28 & 67 & 72 & 2 & 14.3 & 12 & 85.7 & 79 & 73.8 \\
\hline Vancomycin & 93 & 100 & 0 & 0 & 14 & 100 & 0 & 0 & 0 & 0 \\
\hline Linezolid & 90 & 96.8 & 3 & 3.2 & 14 & 100 & 0 & 0 & 3 & 2.8 \\
\hline Moxifloxacin & 46 & 49.5 & 47 & 50.5 & 5 & 35.7 & 9 & 64.3 & 56 & 52.3 \\
\hline Teicoplanin & 82 & 88.2 & 11 & 11.8 & 11 & 78.6 & 3 & 21.4 & 14 & 13 \\
\hline Norfloxacin & 5 & 19.2 & 21 & 80.8 & 0 & 0 & 12 & 100 & 33 & 86.8 \\
\hline Nitrofurantoin & 24 & 92.3 & 2 & 7.7 & 12 & 100 & 0 & 0 & 2 & 5.2 \\
\hline
\end{tabular}

MRSA - Methicillin Resistant Staphylococcus aureus, IP - inpatient OP - Outpatient, *Norfloxacin and Nitrofurantoin was tested for 55 isolates obtained from urine among which 38 isolates were MRSA. 
Some authors ${ }^{18,20-22}$ have predominantly isolated MRSA from skin and soft tissue infections. In our study majority, $35.5 \%(38 / 107)$ of MRSA from urine and $38.5 \%(20 / 52)$ of MSSA from pus samples were reported, however the difference was not statistically significant. Studies ${ }^{6,21,23-26}$ conducted report approximately $90 \%$ of resistance to $\beta$ lactams and erythromycin drugs among MRSA which is consistent with our report. In this study, MRSA isolated from outpatients were $100 \%$ resistant to ampicillin and erythromycin whereas among MSSA it is $45.5 \%$ and $72.7 \%$ respectively. Similarly, higher level of resistance to Co-trimoxazole and Ciprofloxacin is also noted. In this study MRSA from outpatients had high resistance to Ampicillin, Erythromycin, Co-trimoxazole and Ciprofloxacin compared to inpatients (Table: 2 and 3). This increased drug resistance among outpatients might be because the hospital caters mainly to rural population and patients who were referred from peripheral clinics without proper infection control practices. Also, self medication and facilitated self medication through pharmacists may be the reason for increased drug resistance.

Researchers have also reported varying level of resistance to clindamycin and doxycycline among MRSA. Gupta et al. ${ }^{6}$ in his studies reported $75.5 \%$ of MRSA isolates were resistant to clindamycin and in contrast, Mamtora et al. ${ }^{17}$ reported $73 \%$ of MSSA strains were resistant. In our study $50 \%$ of MRSA and $25 \%$ of the MSSA strains were resistant to clindamycin. For doxycycline, some authors ${ }^{6,15}$ have reported resistance ranging from $56 \%$ to $60 \%$ among MRSA and $1.4 \%$ to $12.54 \%$ among MSSA. In this study $71.4 \%$ of MRSA isolates from outpatients were resistant to doxycycline. Among urinary pathogens $94.1 \%$ and $86.8 \%$ of MSSA and MRSA were resistant to Norfloxacin, while only $11.8 \%$ and $5.2 \%$ were resistant to Nitrofurantoin respectively. All MRSA and MSSA isolated from outpatients were $100 \%$ resistant to Norfloxacin and $100 \%$ sensitive to nitrofurantoin, hence nitrofurantoin remain being the drug of choice for urinary tract infections. The varying susceptibility pattern of MRSA to different antibiotics may also get influenced by the antibiotic prescription practice of a physician.

Due to the development of resistance and emergence of MRSA, nowadays vancomycin and linezolid remains the most reliable therapeutic agent for MRSA infections. Most of the studies $5,6,18$ from India including our study report $100 \%$ susceptibility to vancomycin, where only few studies ${ }^{17}$ report resistance. Among MRSA, authors

Table 3. Antibiotic susceptibility pattern of MSSA to various antibiotics

\begin{tabular}{|c|c|c|c|c|c|c|c|c|c|c|c|c|}
\hline \multirow[t]{2}{*}{ Antibiotics } & \multicolumn{5}{|c|}{$\begin{array}{l}\text { Isolate from inpatient } \\
\qquad(41)\end{array}$} & & \multicolumn{4}{|c|}{$\begin{array}{l}\text { Isolate from outpatient } \\
\text { (11) }\end{array}$} & \multicolumn{2}{|c|}{$\begin{array}{c}\text { Total resistance } \\
\text { (IP + OP cases) } \\
n=52\end{array}$} \\
\hline & $\mathrm{S}$ & $\%$ & $\mathrm{R}$ & $\%$ & I & $\%$ & $S$ & $\%$ & $\mathrm{R}$ & $\%$ & $\mathrm{R}$ & $\%$ \\
\hline Ampicillin & 16 & 39 & 25 & 61 & 0 & 0 & 6 & 54.5 & 5 & 45.5 & 30 & 57.7 \\
\hline Erythromycin & 15 & 36.6 & 24 & 58.5 & 2 & 4.9 & 3 & 27.3 & 8 & 72.7 & 32 & 61.5 \\
\hline Doxycycline & 32 & 78 & 9 & 22 & 0 & 0 & 7 & 63.6 & 4 & 36.4 & 13 & 25 \\
\hline Clindamycin & 28 & 68.3 & 12 & 29.3 & 1 & 2.4 & 10 & 90.9 & 1 & 9.1 & 13 & 25 \\
\hline Ciprofloxacin & 18 & 43.9 & 22 & 53.7 & 1 & 2.4 & 5 & 45.5 & 6 & 54.5 & 28 & 53.8 \\
\hline Co-trimoxazole & 19 & 46.3 & 22 & 53.7 & 0 & 0 & 4 & 36.4 & 7 & 63.6 & 29 & 55.8 \\
\hline Vancomycin & 41 & 100 & 0 & 0 & 0 & 0 & 11 & 100 & 0 & 0 & 0 & 0 \\
\hline Linezolid & 41 & 100 & 0 & 0 & 0 & 0 & 11 & 100 & 0 & 0 & 0 & 0 \\
\hline Moxifloxacin & 19 & 46.3 & 22 & 53.7 & 0 & 0 & 6 & 54.5 & 5 & 45.5 & 27 & 51.9 \\
\hline Teicoplanin & 38 & 92.7 & 3 & 7.3 & 0 & 0 & 9 & 81.8 & 2 & 18.2 & 5 & 9.6 \\
\hline Norfloxacin & 1 & 9.1 & 10 & 90.9 & 0 & 0 & 0 & 0 & 6 & 100 & 16 & 94.1 \\
\hline Nitrofurantoin & 9 & 81.8 & 2 & 18.2 & 0 & 0 & 6 & 100 & 0 & 0 & 2 & 11.8 \\
\hline
\end{tabular}

MSSA - Methicillin Sensitive Staphylococcus aureus, IP - inpatient, OP - Outpatient, *Norfloxacin and Nitrofurantoin was tested for 55 isolates obtained from urine among which 17 isolates were MSSA. 
$6,27,28$, have reported approximately $99 \%$ sensitivity to linezolid and our study reports $97.2 \%$ sensitivity. The antibacterial activity of linezolid is around $100 \%$ which is comparable with that of vancomycin and can be used as an alternative in treating MRSA infections. Routine surveillance of hospitalassociated infections including antimicrobial susceptibility pattern of MRSA and formulation of a definite antibiotic policy may be helpful to reduce infection burden caused by MRSA in the hospital.

\section{CONCLUSION}

The present study revealed that MRSA accounts for more than half of the staphylococcal infections, which emphasize to contain the spread by implementing proper infection control practices. This study highlights the high prevalence of MRSA resistant to ampicillin, erythromycin, cotrimoxazole and ciprofloxacin among outpatients and hence these drugs were not suitable for empirical therapy of suspected staphylococcal infections. Nitrofurantoin being sensitive to most of the staphylococcal isolate it remains the drug of choice for treating urinary tract infections. MRSA strains were highly susceptible to vancomycin and linezolid however appropriate prescription of drug based on the antibiotic susceptibility pattern is the need of the hour to avoid the emergence of resistant variants.

\section{ACKNOWLEDGEMENTS}

The authors express their sincere gratitude to The Chairman, The Director (Academics and Research) and Dean, Kanti Devi Medical College \& Research Centre, Mathura and Uttar Pradesh for the support and encouragement.

\section{CONFLICT OF INTEREST}

The authors declare that there is no conflict of interest.

\section{FUNDING}

None.

\section{AUTHORS' CONTRIBUTION}

All authors have made a substantial and intellectual contribution to the work, and approved it for publication.

\section{DATA AVAILABILITY}

All datasets generated and analyzed in this study are included in the manuscript and Table.

\section{ETHICS STATEMENT}

This study does not contain any procedures performed within human participants or animals.

\section{REFERENCES}

1. Rajkumar S, Sistla S, Manoharan $M$, Sugumar $M$, Nagasundaram N, Parija SC, Ray P, Bakthavatchalam YD, Veeraraghavan B, Kapil A, Walia K, Ohri VC. Prevalence and genetic mechanisms of antimicrobial resistance in Staphylococcus species: A multicentre report of the indian council of medical research antimicrobial resistance surveillance network. Indian J Med Microbiol., 2017; 35(1): 53-60. https://doi. org/10.4103/ijmm.IJMM_16_427.

2. Saseedharan $S$, Sahu M, Chaddha R, Pathrose E, Bal A, Bhalekar P, Sekar P, Krishnan P. Epidemiology of diabetic foot infections in a reference tertiary hospital in India. Braz J Microbiol., 2018; 49(2): 401-6. https:// doi.org/10.1016/j.bjm.2017.09.003

3. Kulkarni AP, Nagvekar VC, Veeraraghavan B, Warrier AR, Ts D, Ahdal J, Jain R. Current Perspectives on Treatment of Gram-Positive Infections in India: What Is the Way Forward? Interdiscip Perspect Infect Dis., 2019; 2019: 7601847. https://doi.org/10.1155/2019/7601847

4. Wangai FK, Masika MM, Maritim MC, Seaton RA. Methicillin-resistant Staphylococcus aureus (MRSA) in East Africa: red alert or red herring? BMC Infect Dis., 2019; 19(1): 596. https://doi.org/10.1186/s12879019-4245-3

5. Moolchandani K, Sastry AS, Deepashree R, Sistla S, Harish BN, Mandal J. Antimicrobial Resistance Surveillance among Intensive Care Units of a Tertiary Care Hospital in Southern India. J Clin Diagn Res., 2017; 11(2): DC01-DC07. https://doi.org/10.7860/ JCDR/2017/23717.9247

6. Gupta V, Pachori R, Goyal RK. Antibiotic susceptibility pattern of Staphylococcus aureus in tertiary care hospital, SRMSIMS, Bareilly, U.P. Int J Community Med Public Health, 2017; 4(8): 2803-9. https://doi. org/10.18203/2394-6040.ijcmph20173327

7. Winn Jr. CW, Allen SD, Janda WM, Koneman EW, Procop GW, Schreckenberger PC, Woods GL. Koneman's color atlas and textbook of diagnostic microbiology, 2006; pp. 623-662. 6th Ed. Lippincott Williams \& Wilkins, Baltimore.

8. CLSI. Performance Standards for Antimicrobial Susceptibility Testing. $27^{\text {th }}$ ed. CLSI supplement M100. Wayne, PA: Clinical and Laboratory Standards Institute; 2017.

9. Verma S, Joshi S, Chitnis V, Hemwani N, Chitnis D. Growing problem of methicillin resistant staphylococci-Indian scenario. Indian J Med Sci., 2000; 54(12): 53540. 
10. Abdalla $A E$, Kabashi $A B$, Elobaid ME, Hamed $N M H$, Modawyi WA, Alameen AAM, Abosalif KOA and Ejaz $\mathrm{H}$. Methicillin and Inducible Clindamycin-Resistant Staphylococcus aureus Isolated from Postoperative Wound Samples. J Pure App/ Microbiol., 2019; 13(3):1605-9. https://doi.org/10.22207/JPAM.13.3.33

11. Udobi CE, Obajuluwa AF, Onaolapo JA. Prevalence and antibiotic resistance pattern of methicillin-resistant Staphylococcus aureus from an orthopaedic hospital in Nigeria. BioMed Research International, 2013; 2013: 8604674. https://doi.org/10.1155/2013/860467

12. Guzman-Blanco M, Mejia C, Isturiz R, Alvarez C, Bavestrello L, Gotuzzo E, Labarca J, Luna CM, Rodriguez-Noriega E, Salles MJ, Zurita J, Seas C. Epidemiology of methicillin-resistant Staphylococcus aureus (MRSA) in Latin America. Int J Antimicrob Agents., 2009; 34(4): 304-8. https://doi.org/10.1016/j. ijantimicag.2009.06.005

13. Ntirenganya C, Manzi O, Muvunyi CM, Ogbuagi O. High prevalence of antimicrobial resistance among common bacterial isolates in a tertiary healthcare facility in Rwanda. Am J Trop Med Hyg., 2015; 92(4): 865-70. https://doi.org/10.4269/ajtmh.14-0607

14. Jimenez JN, Ocampo AM, Vanegas JM, Rodriguez EA, Mediavilla JR, Chen L, Muskus CE, Velez LA, Rojas C, Restrepo AV, Ospina S, Garces C, Franco L, Bifani P, Kreiswirth BN, Correa MM. CC8 MRSA Strains Harboring SCCmec Type IVc are Predominant in Colombian Hospitals. PLOS ONE, 2012; 7(6): e38576. https://doi.org/10.1371/journal.pone.0038576

15. Trivedi MB, Vegad M, Soni S. Prevalence of methicillinresistant Staphylococcus aureus in various clinical samples in a tertiary-care hospital. Int J Med Sci Public Health, 2015; 4(12): 1735-8. https://doi.org/10.5455/ ijmsph.2015.30062015358

16. Kumari N, Mohapatra TM, Singh YI.Prevalence of Methicillin-resistant Staphylococcus aureus (MRSA) in a Tertiary-Care Hospital in Eastern Nepal. JNMA J Nepal Med Assoc., 2008; 47(170): 53-6. https://doi. org/10.31729/jnma.309

17. Mamtora D, Saseedharan S, Bhalekar P, Katakdhond S. Microbiological profile and antibiotic susceptibility pattern of Gram-positive isolates at a tertiary care hospital. J Lab Physicians, 2019; 11(2): 144-8. https:// doi.org/10.4103/JLP.JLP_173_18

18. Pai V, Rao VI, Rao SP. Prevalence and Antimicrobial Susceptibility Pattern of Methicillin-resistant Staphylococcus aureus [MRSA] Isolates at a Tertiary Care Hospital in Mangalore, South India. J Lab Physicians, 2010; 2(2): 82-4. https://doi. org/10.4103/0974-2727.72155

19. Singh L, Cariappa MP, Das NK. Drug sensitivity pattern of various Staphylococcus species isolated at a tertiary care hospital. Med J Armed Forces India, 2016; 72(Suppl 1):S62-S66. https://doi.org/10.1016/j. mjafi.2016.07.009

20. Dubey D, Rath S, Sahu MC, Pattnaik L, Debata NK, Padhy RN. Surveillance of infection status of drug resistant Staphylococcus aureus in an Indian teaching hospital. Asian Pac J Trop Dis., 2013; 3(2): 133-42. https://doi. org/10.1016/S2222-1808(13)60057-2

21. Anupurba S, Sen MR, Nath G, Sharma BM, Gulati AK, Mohapatra TM. Prevalence of methicillin resistant Staphylococcus aureus in tertiary referral hospital in Eastern Uttar Pradesh. Indian J Med Microbiol., 2003; 21(1): 49-51.

22. Chaturvedi P, Singh AK, Singh AK, Shukla S, Agarwal L. Prevalence of Mupirocin Resistant Staphylococcus aureus Isolates Among Patients Admitted to a Tertiary Care Hospital. N Am J Med Sci., 2014; 6(8): 403-7. https://doi.org/10.4103/1947-2714.139293

23. Kandle SK, Ghatole MP, Takpere AY, Hittinhalli VB, Yemul VL. Bacteriophage typing and antibiotic sensitivity pattern of Staphylococcus aureus from clinical specimen in and around Solapur (South Maharashtra). J Commun Dis., 2003; 35(1): 17-23.

24. Hanumanthappa AR, Chandrappa NR, Rajasekharappa MG. Prevalence of methicillin resistant Staphylococcus aureus in Karnataka. Indian J Pathol Microbiol., 2003; 46(1): 129-32.

25. Indian Network for Surveillance of Antimicrobial Resistance (INSAR) group, India. Methicillin resistant Staphylococcus aureus (MRSA) in India: Prevalence \& susceptibility pattern. Indian J Med Res., 2013; 137(2): 363-9.

26. Gade ND, Qazi MS. Fluoroquinolone Therapy in Staphylococcus aureus Infections: Where Do We Stand? J Lab Physicians., 2013; 5(2): 109-12. https:// doi.org/10.4103/0974-2727.119862

27. Stevens DL, Smith LG, Bruss JB. Randomized comparison of Linezolid versus oxacillin dicloxacillin treatment of complicated skin and soft tissue infections. Antimicrob Agents Chemother., 2000; 44(12): 3408-13. https://doi. org/10.1128/AAC.44.12.3408-3413.2000

28. Tsiodras S, Gold HS, Sakoulas G, Eliopoulos GM, Wennersten C, Venkataraman L, Moellering RC, Ferraro MJ. Linezolid resistance in a clinical isolate of Staphylococcus aureus. Lancet, 2001; 358(9277): 2078. https://doi.org/10.1016/S0140-6736(01)05410-1 